\title{
Soil-borne microorganisms and soil-type affect pyrrolizidine alkaloids in Jacobaea vulgaris
}

\author{
Lotte Joosten • Patrick P. J. Mulder • \\ Peter G. L. Klinkhamer • Johannes A. van Veen
}

Received: 1 October 2008 / Accepted: 9 March 2009 / Published online: 20 March 2009

(C) The Author(s) 2009. This article is published with open access at Springerlink.com

\begin{abstract}
Secondary metabolites like pyrrolizidine alkaloids (PAs) play a crucial part in plant defense. We studied the effects of soil-borne microorganisms and soil-type on pyrrolizidine alkaloids in roots and shoots of Jacobaea vulgaris. We used clones of two genotypes from a dune area (Meijendel), propagated by tissue culture and grown on two sterilized soils and sterilized soils inoculated with $5 \%$ of non-sterilized soil of either of the two soil-types. Soil-borne microorganisms and soil-type affected the composition of PAs. By changing the composition rather than the
\end{abstract}

Responsible Editor: Harsh P. Bais.

L. Joosten $(\bowtie) \cdot$ P. G. L. Klinkhamer · J. A. van Veen

Institute of Biology, Leiden University,

P.O. Box 9516, Kaiserstraat 63,

2300 RA Leiden, The Netherlands

e-mail: 1.joosten@biology.leidenuniv.nl

P. G. L. Klinkhamer

e-mail: p.g.l.klinkhamer@biology.leidenuniv.nl

J. A. van Veen

e-mail: h.vanveen@nioo.knaw.nl

L. Joosten · J. A. van Veen

Netherlands Institute of Ecology (NIOO-KNAW),

P.O. Box 40, 6666 ZG Heteren, The Netherlands

P. P. J. Mulder

RIKILT-Institute of Food Safety,

P.O. Box 230, 6700 AE Wageningen, The Netherlands

e-mail: patrick.mulder@wur.nl total concentration below and aboveground, plants have a more complex defense strategy than formerly thought. Interestingly, a stronger negative effect on plant growth was found in sterilized soils inoculated with their 'own' microbial community suggesting that pathogenic and/or other plant inhibiting microorganisms were adapted to their 'own' soil conditions.

Keywords Chemical diversity . Plant defense . Plant-microbial interaction - Senecio jacobaea . Soil microbial community

$\begin{array}{ll}\text { Abbreviations } \\ \text { PA } & \text { Pyrrolizidine alkaloid } \\ \text { LC } & \text { Liquid chromatography } \\ \text { MS } & \text { Mass spectrometer } \\ \text { N } & \text { Nitrogen }\end{array}$

\section{Introduction}

Many plants synthesize a diversity of compounds as a defense against herbivores and pathogens. This diversity seems to be one of the strategies of the plant to cope with the great variety of potential environmental threats. The composition of defense compounds depends on the genotype of the plants, showing variation within species and even among individual plants within a population. All this genetically based variability can also be influenced by the 
abiotic and biotic environment (Karban and Baldwin 1997; Agrawal 1998; Macel and Klinkhamer 2009).

When the root system is exposed to belowground organisms (e.g. herbivore insects, nematodes, root pathogens and mycorrhizal fungi) plants can show several direct defense responses in the shoots that may affect aboveground herbivores and, thus plant fitness (van Loon et al. 1998; van der Putten et al. 2001; Paul et al. 2000; Gange et al. 2002; Dicke and Hilker 2003; van Dam et al. 2003; Bezemer et al. 2005; Bezemer and van Dam 2005).

Jacobaea vulgaris (syn Senecio jacobaea) is a suitable system to study chemical defense, because it contains a well studied group of defense compounds; pyrrolizidine alkaloids (PAs). The concentration and composition of PAs in J. vulgaris depend on the genotype and environment (Vrieling et al. 1993; Hol et al. 2003; Macel et al. 2004). Macel and Klinkhamer (2009) noticed, in a field experiment, that in genotypes of $J$. vulgaris the composition of defense compounds (pyrrolizidine alkaloids) changed compared to the initial composition of clones in the laboratory. The composition also differed between the aboveground parts of clones grown on two different experimental field sites. This raises the question if soil-type and/or soil-borne microorganisms could have an impact on defense compounds in below and aboveground plant parts.

We expect that if the net effect of the soil-borne microbial community on plant growth is negative the plant responds by increasing its PA concentration in order to suppress the effect of pathogens. However, because the production of these defense compounds takes place in the roots, the interactions with soilborne pathogens can also reduce the production of PAs by inducing root damage and increasing the shoot/root ratios of the plants (Frischknecht et al. 2001; Hol et al. 2003) in combination with a reduced plant growth (Bever 1994; Klironomos 2002).

In addition the PA composition could be changed by activating particular transforming enzymes that are responsible for the diversification of the PAs (Hartmann and Dierich 1998).

The most recent study on the defense of $J$. vulgaris indicated that plants with high jacobine levels suppress the growth of microbes by inducing a lower diversity of fungi in the rhizosphere compared to plants lacking high levels of jacobine alkaloids (Kowalchuk et al. 2006). This implies that the PA composition may have an important influence on fungi in the rhizosphere. Interestingly, the $J$. vulgaris alkaloids; retrorsine and retrorsine $N$-oxide showed to have inhibitory effects on mycelium growth of several plant-associated fungi (Hol and van Veen 2002). Apart from the studies mentioned above, so far little is known about the specific effects of different PAs on soil-borne microorganisms.

In the present study we tested if soil-borne microbial communities effect PA concentration and composition in J. vulgaris. In a laboratory experiment we grew cloned plants of two genotypes, on two different sterilized soils and sterilized soils inoculated with 5\% of non-sterilized soil of either of the two soil-types. To obtain a detailed picture of the PA concentration and composition of the plants after 6 weeks, LC-MS/ MS was used to analyze the root and shoot extracts.

\section{Material and methods}

\section{Experimental design}

We selected two different genotypes with high (A) and low (B) total plant PA concentration, which originated from different populations at Meijendel. The genotypes were propagated by tissue culture. Eight cloned replicates per genotype per treatment were planted in two different sterilized soil-types in $1.3 \mathrm{~L}$ pots. The two soil-types used were 'Meijendel soil', calcareous sand from a coastal dune area in the North of The Hague $\left(52^{\circ} 9^{\prime} \mathrm{N}, 4^{\circ} 22^{\prime} \mathrm{E}\right)$ and 'Heteren soil', a mixture of sand and potting soil from an experimental garden that has been in use since $1994\left(51^{\circ} 57^{\prime} \mathrm{N}\right.$, $\left.5^{\circ} 44^{\prime} \mathrm{E}\right)$ in the Netherlands. For each soil we compared three treatments 1 . control (sterilized soil) 2. sterilized soil treated with inoculum (5\%) of non sterilized soil of the same origin 3. sterilized soil treated with inoculum (5\%) of the other soil-type. In total this resulted in 96 plants ( 8 replicates $* 2$ genotypes $* 2$ soils $* 3$ treatments). Soil sterilization was done by 25 kilo Gray gammaradiation (Isotron, Ede, The Netherlands). Soil for the inocula was collected within a radius of one meter from naturally occurring $J$. vulgaris plants.

Plants were randomly distributed and grown for 6 weeks in a climate room (relative humidity $70 \%$, light $16 \mathrm{~h}$ at $20^{\circ} \mathrm{C}$, dark $8 \mathrm{~h}$ at $20^{\circ} \mathrm{C}$ ). Demi-water was given three times a week with additions of $20 \mathrm{ml}$ of Steiner nutrient solution (Steiner 1968) once every 
fortnight. After 6 weeks the plants were harvested and cut above the root crown by a scissor. Harvested plant parts (shoots and roots) were kept at $-25^{\circ} \mathrm{C}$ for approximately 2 weeks before being freeze-dried for $72 \mathrm{~h}$ under vacuum with a collector temperature of $-55^{\circ} \mathrm{C}$ (an Labconco Free Zone ${ }^{\circledR} 12$ L Freeze Dry System). Plant dry mass was measured as a proxy for the net effect of the inoculum on plant growth.

Pyrrolizidine alkaloid analysis

Freeze-dried plant material (approximately $10 \mathrm{mg}$ ) was extracted with $2 \%$ formic acid in a 1 to 100 weight to volume ratio. Heliotrine, monocrotaline and monocrotaline $\mathrm{N}$-oxide were added as internal standards to the extraction solvent at a concentration of $1 \mu \mathrm{g} / \mathrm{ml}$. After centrifugation an aliquot of the solution $(10 \mu \mathrm{l})$ was diluted with water $(990 \mu \mathrm{l})$ and injected in the LC-MS/MS system (an Agilent HP1100 HPLC system coupled to a Waters Micromass Micro tandem mass spectrometer).

Chromatographic separation was achieved on a Waters Xbridge $150 \times 3.0 \mathrm{~mm}$ HPLC column, run with a water/acetonitrile linear gradient containing $0.05 \%$ ammonia at a flow of $0.4 \mathrm{ml} / \mathrm{min}$. The gradient started at $100 \%$ water and during analysis the acetonitrile percentage was raised to $70 \%$.

The MS system was operated in positive electrospray mode and data were recorded in multiple monitoring mode using one selected precursor ion to product ion transition per compound. Cone and collision energy settings were optimized for the individual compounds. Obtained peak areas were internally calibrated using the internal standards and the individual compounds were quantified against a standard solution of the PAs in water. Fourteen individual PA standards were available for this study, representing over $90 \%$ of the total amount of PAs present in the plants extracts. The remaining PAs, being tertiary base as well as $N$ oxides, were quantified by using the mean response of the tertiary amine standards and the $\mathrm{N}$-oxide standards, respectively. Data processing was conducted with Masslynx 4.0 software.

\section{Data analysis}

Plant dry mass, shoot/root ratio and total PA concentrations in shoots and roots were statistically analyzed by GLM (General Linear Model) univariate analyses procedure. With PA concentration as the dependent variable, genotype (Genotype A and B), soil-type (Meijendel and Heteren) and inoculum (Sterilized, Meijendel and Heteren soil inoculum) as fixed factors and plant dry mass and shoot/root ratio as covariates.

In order to assess the effects of soil-type and inoculum treatments on the composition of the PAs in roots and shoots for each genotype we used discriminant analyses to predict to which treatment a sample belonged on basis of its alkaloid pattern. An F-test (Wilks' lambda) was used to test if the four discriminant models (roots and shoots of both genotypes) as a whole were significant. The relative concentrations (expressed as the percentage of the total PA concentration) and the total PA concentration were included as independents variables. All tests were conducted with SPSS 15.0 for Windows.

\section{Results}

Plant dry mass

Soil-type had a greater impact on plant dry mass than genotype or inoculum (Table 1). The mean dry mass of plants grown on the two soil-types, Heteren and Meijendel was across treatments, 1.42 and $0.48 \mathrm{~g}$ respectively (Fig. 1a). Mean plant dry mass of genotype A was $0.82 \mathrm{~g}$, while that of genotype B was $1.09 \mathrm{~g}$. Mean dry mass was highest on sterilized soils (HS and MS) indicating an overall negative effect of the soil borne microbial community. Plant dry mass was lowest on sterilized soils inoculated with non-sterilized soil of the same origin ( $\mathrm{HH}$ and $\mathrm{MM}$ ) leading to a significant soil-type $\times$ treatment interaction. In addition the effects on plant dry mass depended on the three-way interaction between genotype, soil-type and inoculum treatment.

\section{Shoot/root ratio}

The largest difference in shoot/root ratio was found between the two genotypes (Table 1). Mean shoot/ root ratio of genotype A was 0.59 , while that of genotype B was 0.38 (Fig. 1b). Shoot/root ratio was significantly higher in Heteren soils than in Meijendel soil, 0.42 and 0.55 respectively. Inoculation lowered the shoot/root ratio of the plants especially when soils inoculated were inoculated with non-sterilized soil of 
Table 1 ANOVA of the effect of genotype, soil-type and inoculum treatment on plant dry mass, shoot/root-ratio of Jacobaea vulgaris

\begin{tabular}{|c|c|c|c|c|c|}
\hline Dependent variables & Fixed factors & df $(\mathrm{k}-1)$ & Df $(\mathrm{N}-\mathrm{k})$ & $\mathrm{F}$ & $\mathrm{P}$ \\
\hline \multirow[t]{9}{*}{ Plant dry mass } & Genotype & 1 & 94 & 88.413 & 0.000 \\
\hline & Soil-type & 1 & 94 & $1,041.942$ & 0.000 \\
\hline & Inoculum treatment & 2 & 93 & 63.355 & 0.000 \\
\hline & Genotype x soil-type & 1 & 94 & 31.732 & 0.000 \\
\hline & Genotype $\mathrm{x}$ inoculum treatment & 2 & 93 & 2.506 & 0.088 \\
\hline & Soil-type $\mathrm{x}$ inoculum treatment & 2 & 93 & 49.908 & 0.000 \\
\hline & Genotype $\mathrm{x}$ soil-type $\mathrm{x}$ inoculum treatment & 2 & 93 & 4.731 & 0.011 \\
\hline & Error & 84 & & & \\
\hline & Total & 96 & & & \\
\hline \multirow[t]{9}{*}{ Shoot/root ratio } & Genotype & 1 & 94 & 99.704 & 0.000 \\
\hline & Soil-type & 1 & 94 & 43.309 & 0.000 \\
\hline & Inoculum treatment & 2 & 93 & 26.397 & 0.000 \\
\hline & Genotype x soil-type & 1 & 94 & 7.192 & 0.009 \\
\hline & Genotype $\mathrm{x}$ inoculum treatment & 2 & 93 & 2.966 & 0.057 \\
\hline & Soil-type $\mathrm{x}$ inoculum treatment & 2 & 93 & 8.437 & 0.000 \\
\hline & Genotype $\mathrm{x}$ soil-type $\mathrm{x}$ inoculum treatment & 2 & 93 & 3.308 & 0.041 \\
\hline & Error & 84 & & & \\
\hline & Total & 96 & & & \\
\hline
\end{tabular}

the other soil-type (HM and $\mathrm{MH})$. In addition the effects on shoot/root ratio depended on the three-way interaction between genotype, soil-type and inoculum treatment.

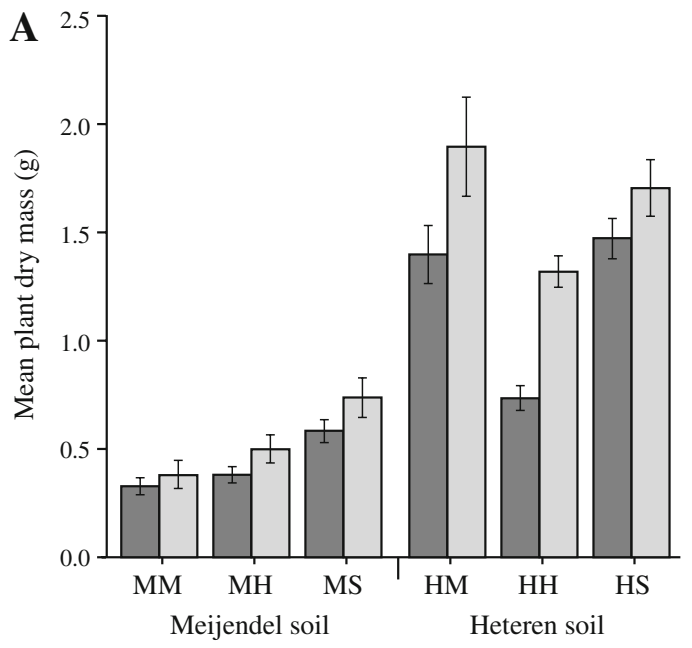

Fig. 1 A Plant dry mass (Mean \pm SE, $n=8$ ) per soil-type per inoculum treatment of both Jacobaea vulgaris genotypes. B Shoot/root ratio (Mean \pm SE, $n=8$ ) per soil-type per treatment of both Jacobaea vulgaris genotypes. Left bar = genotype A; Right bar $=$ genotype $\mathrm{B} ; M M=$ sterilized Meijendel soil inoculated with non-sterilized Meijendel soil; $M H=$ sterilized
Total pyrrolizidine alkaloid concentration

Soil-type, did not significantly affect the mean total PA concentration of roots and shoots (Table 2). In

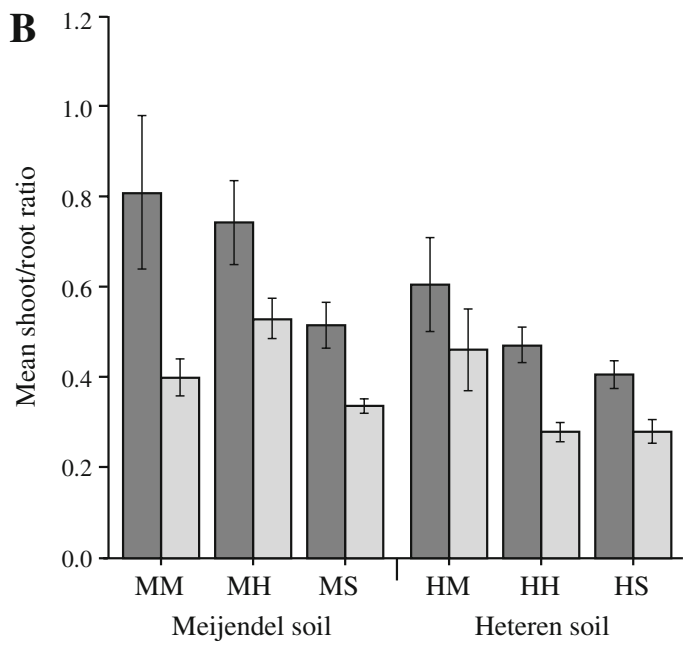

Meijendel soil inoculated with non-sterilized Heteren soil; $M S=$ sterilized Meijendel soil; $H M=$ sterilized Heteren soil inoculated with non-sterilized Meijendel soil; $H H=$ sterilized Heteren soil inoculated with non-sterilized Heteren soil; $H S=$ sterilized Heteren soil 
Table 2 ANOVA of the effect of shoot dry mass, root dry mass, genotype, soil-type and inoculum treatment on the mean total PA concentration of roots and shoots

\begin{tabular}{|c|c|c|c|c|c|}
\hline Dependent variables & Fixed factors & df $(\mathrm{k}-1)$ & Df $(\mathrm{N}-\mathrm{k})$ & $\mathrm{F}$ & $\mathrm{P}$ \\
\hline \multirow[t]{11}{*}{ Total PA conc. root } & Root dry mass (covariate) & 1 & 94 & 0.925 & 0.339 \\
\hline & Shoot dry mass (covariate) & 1 & 94 & 1.314 & 0.255 \\
\hline & Genotype & 1 & 94 & 128.023 & 0.000 \\
\hline & Soil-type & 1 & 94 & 0.407 & 0.525 \\
\hline & Inoculum treatment & 2 & 93 & 9.296 & 0.000 \\
\hline & Genotype x soil-type & 1 & 94 & 3.282 & 0.074 \\
\hline & Genotype $\mathrm{x}$ inoculum treatment & 2 & 93 & 0.368 & 0.693 \\
\hline & Soil-type $\mathrm{x}$ inoculum treatment & 2 & 93 & 2.170 & 0.121 \\
\hline & Genotype $\mathrm{x}$ soil-type $\mathrm{x}$ inoculum treatment & 2 & 93 & 3.484 & 0.035 \\
\hline & Error & 82 & & & \\
\hline & Total & 96 & & & \\
\hline \multirow[t]{11}{*}{ Total PA conc. root } & Root dry mass (covariate) & 1 & 94 & 1.244 & 0.268 \\
\hline & Shoot dry mass (covariate) & 1 & 94 & 1.762 & 0.188 \\
\hline & Genotype & 1 & 94 & 4.038 & 0.048 \\
\hline & Soil-type & 1 & 94 & 0.425 & 0.516 \\
\hline & Inoculum treatment & 2 & 93 & 0.854 & 0.430 \\
\hline & Genotype x soil-type & 1 & 94 & 17.370 & 0.000 \\
\hline & Genotype $\mathrm{x}$ inoculum treatment & 2 & 93 & 8.410 & 0.000 \\
\hline & Soil-type $\mathrm{x}$ inoculum treatment & 2 & 93 & 1.122 & 0.330 \\
\hline & Genotype $\mathrm{x}$ soil-type $\mathrm{x}$ inoculum treatment & 2 & 93 & 11.740 & 0.000 \\
\hline & Error & 82 & & & \\
\hline & Total & 96 & & & \\
\hline
\end{tabular}

contrast to our expectation, shoot and root dry mass and shoot/root ratio did not significantly affect total PA concentration either. Genotype had the largest impact on the total PA concentration in the roots (Fig. 2a). Across soil-type and treatments, the total PA concentration in the roots of genotype A and B, was $11.3 \mathrm{mg}$ and $6.6 \mathrm{mg} / \mathrm{g}$ dry root material respectively. The mean total PA concentrations in the shoots of genotypes $\mathrm{A}$ and $\mathrm{B}$, was $8.5 \mathrm{mg}$ and $7.7 \mathrm{mg} / \mathrm{g}$ dry shoot material, respectively. The PA concentration of the two genotypes was affected differently by the two soil-types and the combination of soil-type and treatment as can be seen by the two and three way interactions (Table 2). Inoculation with non-sterilized soils decreased the total PA concentration in the roots of both genotypes. In addition inoculation decreased the total PA concentration in the shoots of genotype B. For genotype A, the effect of inoculation was less clear.
Pyrrolizidine alkaloid composition

In this study in total 13 different PA $N$-oxides and 13 different tertiary amines were detected in root and shoot extracts (Table 3). These PAs have all been described for Jacobaea vulgaris (Witte et al. 1992). However, compared to previous studies on J. vulgaris plants, a high number of PAs was detected simultaneously within a single genotype (Witte et al. 1992; Macel et al. 2002; Macel et al. 2004; Kowalchuk et al. 2006). This is in part due to the low concentrations of PAs that can be detected with LC-MS/MS in plant material compared to previously used GC-NPD and GC-MS techniques (Wuilloud et al. 2004; Betteridge and Colegate 2005). Another advantage of LC-MS/ MS is that it can determine both $N$-oxides and tertiary amine directly, without the necessity of reduction of $\mathrm{N}$-oxides to the corresponding tertiary amines, as is required for GC-based methods. As a result the 


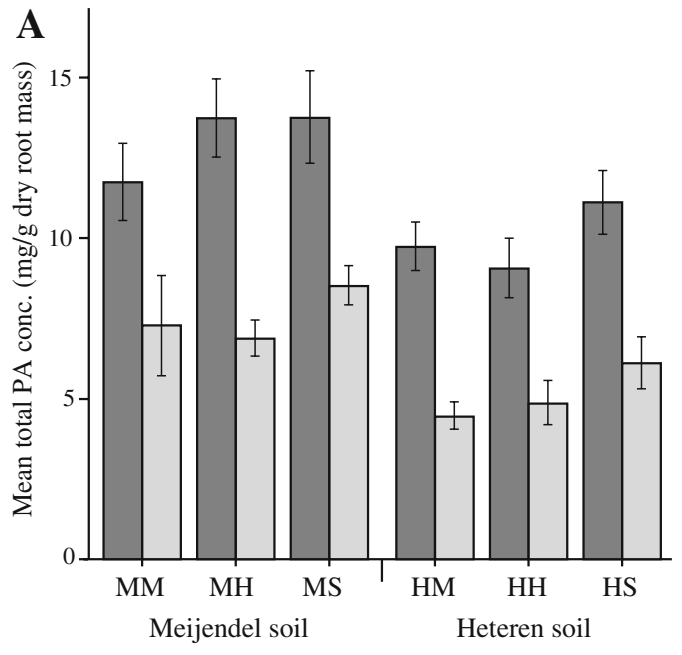

Fig. 2 A Total PA concentration (Mean \pm SE, $n=8$ ) for root per soil-type per inoculum treatment of both Jacobaea vulgaris genotypes. B Total PA concentration (Mean $\pm \mathrm{SE}, n=8$ ) for shoot per soil-type per inoculum treatment of both Jacobaea vulgaris genotypes. Left bar = genotype A; Right bar = genotype $\mathrm{B} ; M M=$ sterilized Meijendel soil inoculated with

number of PAs detected in the extracts is effectively doubled. Moreover, the relative proportion of PA $N$ oxides and tertiary amines can be accurately determined for each individual PA. One individual PA type could not be identified with certainty but based on its retention time and molecular mass $\left(367, \mathrm{M}+\mathrm{H}^{+}: 368\right)$ it is probably eruciflorine $\mathrm{N}$-oxide. In the roots of

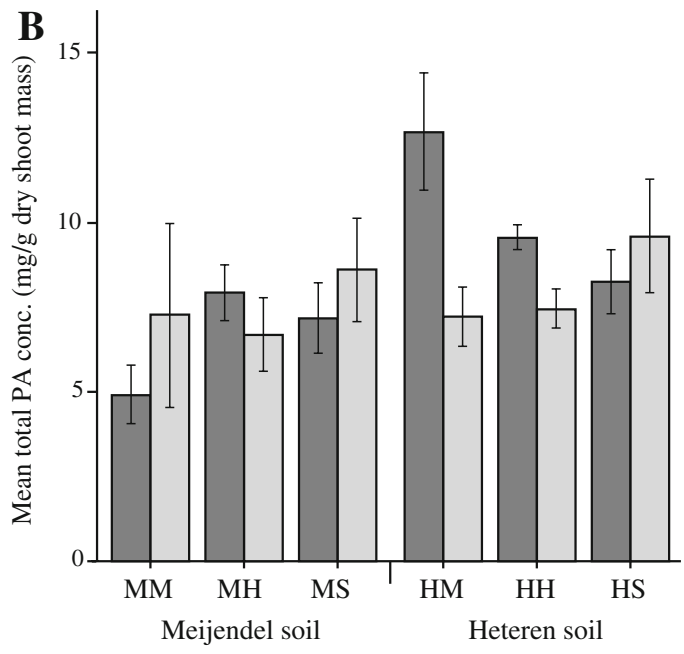

non-sterilized Meijendel soil; $M H=$ sterilized Meijendel soil inoculated with non-sterilized Heteren soil; $M S=$ sterilized Meijendel soil; $H M=$ sterilized Heteren soil inoculated with non-sterilized Meijendel soil; $H H=$ sterilized Heteren soil inoculated with non-sterilized Heteren soil; $H S=$ sterilized Heteren soil

both genotypes nearly $98 \%$ of all alkaloids were $N$ oxides. Senecionine $N$-oxide was the most abundant PA with a percentage up to $76 \%$ of the total PA concentration in the roots. The average percentage of $\mathrm{N}$-oxides in the shoots was much lower and the PA composition was more diverse. In the shoot of genotype A, $35 \%$ of the PAs occurred as tertiary amines and in
Table 3 The concentration of different PAs in roots and shoots (Mean \pm SE, $n=96$ )

\begin{tabular}{llllll}
\hline PAs (mg/g plant dry mass) & Root & & Shoot & \\
\cline { 2 - 3 } \cline { 5 - 6 } & N-oxide & Tertiary amine & & N-oxide & Tertiary amine \\
\hline 1. Senecionine & $6.1332 \pm 0.2632$ & $0.0768 \pm 0.0056$ & $2.1148 \pm 0.0973$ & $0.1933 \pm 0.0145$ \\
2. Seneciphylline & $1.1884 \pm 0.0394$ & $0.0023 \pm 0.0011$ & & $1.7267 \pm 0.0995$ & $0.1674 \pm 0.0120$ \\
3. Acetyl-seneciphylline & $0.4370 \pm 0.0211$ & $0.0077 \pm 0.0006$ & $0.0257 \pm 0.0025$ & $0.0072 \pm 0.0014$ \\
4. Integerrimine & $0.5707 \pm 0.0273$ & $0.0046 \pm 0.0003$ & $0.3166 \pm 0.0133$ & $0.0163 \pm 0.0013$ \\
5. Retrorsine & $0.0992 \pm 0.0102$ & $0.0035 \pm 0.0004$ & $0.0811 \pm 0.0049$ & $0.0066 \pm 0.0007$ \\
6. Jacobine & $0.1961 \pm 0.0111$ & $0.0658 \pm 0.0047$ & $0.9370 \pm 0.0823$ & $1.8734 \pm 0.1063$ \\
7. Jacoline & $0.0050 \pm 0.0003$ & $0.0031 \pm 0.0001$ & $0.0232 \pm 0.0020$ & $0.0375 \pm 0.0027$ \\
8. Jacozine & $0.0067 \pm 0.0003$ & $0.0003 \pm 4.9 \mathrm{E}-5$ & $0.0169 \pm 0.0007$ & $0.0161 \pm 0.0010$ \\
9. Jaconine & $0.0002 \pm 4.1 \mathrm{E}-5$ & - & $0.0036 \pm 0.0004$ & $0.0072 \pm 0.0012$ \\
10. Dehydro-jaconine & - & - & - & $0.0003 \pm 5.9 \mathrm{E}-5$ \\
11. Erucifoline & $0.0610 \pm 0.0017$ & $0.0071 \pm 0.0005$ & $0.1459 \pm 0.0087$ & $0.0462 \pm 0.0026$ \\
12. Acetyl-erucifoline & $0.0075 \pm 0.0006$ & - & $0.2490 \pm 0.0119$ & $0.0176 \pm 0.0011$ \\
13. Riddelliine & $0.0339 \pm 0.0011$ & $0.0002 \pm 3.9 \mathrm{E}-5$ & $0.0674 \pm 0.0003$ & $0.0027 \pm 0.0002$ \\
14. 368 (eruciflorine) & $0.0188 \pm 0.0009$ & - & $0.0111 \pm 0.0004$ & - \\
Total PA concentration & $8.7577 \pm 0.3362$ & $0.1919 \pm 0.0116$ & $5.7187 \pm 0.2228$ & $2.3921 \pm 0.1134$ \\
\hline & & & & &
\end{tabular}


genotype B, nearly $25 \%$. Senecionine $N$-oxide, seneciphylline and jacobine were the three major PAs present in the shoots. Jacobine is mainly responsible for the relatively high amount of tertiary amines found in the shoots. Less than $10 \%$ of senecionine and seneciphylline is present in the shoots as tertiary amine, for jacobine this is $65 \%$.

Effect of soil-type and inoculum treatment on the pyrrolizidine alkaloid composition

In order to assess the effects of the treatments on the composition of the PAs in shoots and roots we
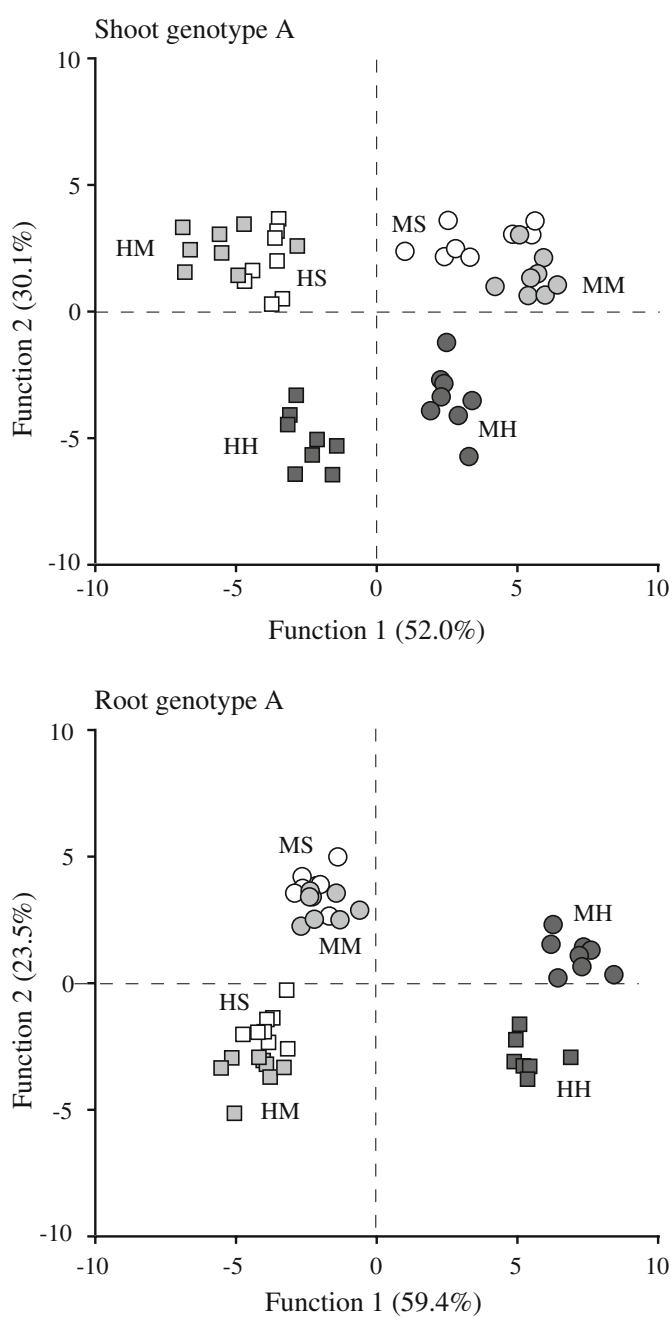

Fig. 3 Four combined-group scatterplots showing the discriminant scores of the cases on discriminant function 1 and 2 generated by Classify Discriminant Analysis per genotype per plant part. $M M=$ Sterilized Meijendel soil inoculated with Meijendel soil; $M H=$ Sterilized Meijendel performed four discriminant analyses (roots and shoots of two genotypes). In all four analyses the relative concentration of different PAs discriminated the six treatment groups significantly (Meijendel soil inoculated with Meijendel soil Heteren soil or sterile: MM, MH, MS and Heteren soil inoculated with Meijendel soil Heteren soil or sterile: HM HH, HS). In all four analyses all eight replicates per treatment clustered together (Fig. 3). In total five functions were needed to classify all cases correctly. The first two functions classified around $80 \%$ of all the cases correctly for all four discriminant analyses. Figure 4 shows the structure matrixes, presenting the correlations of
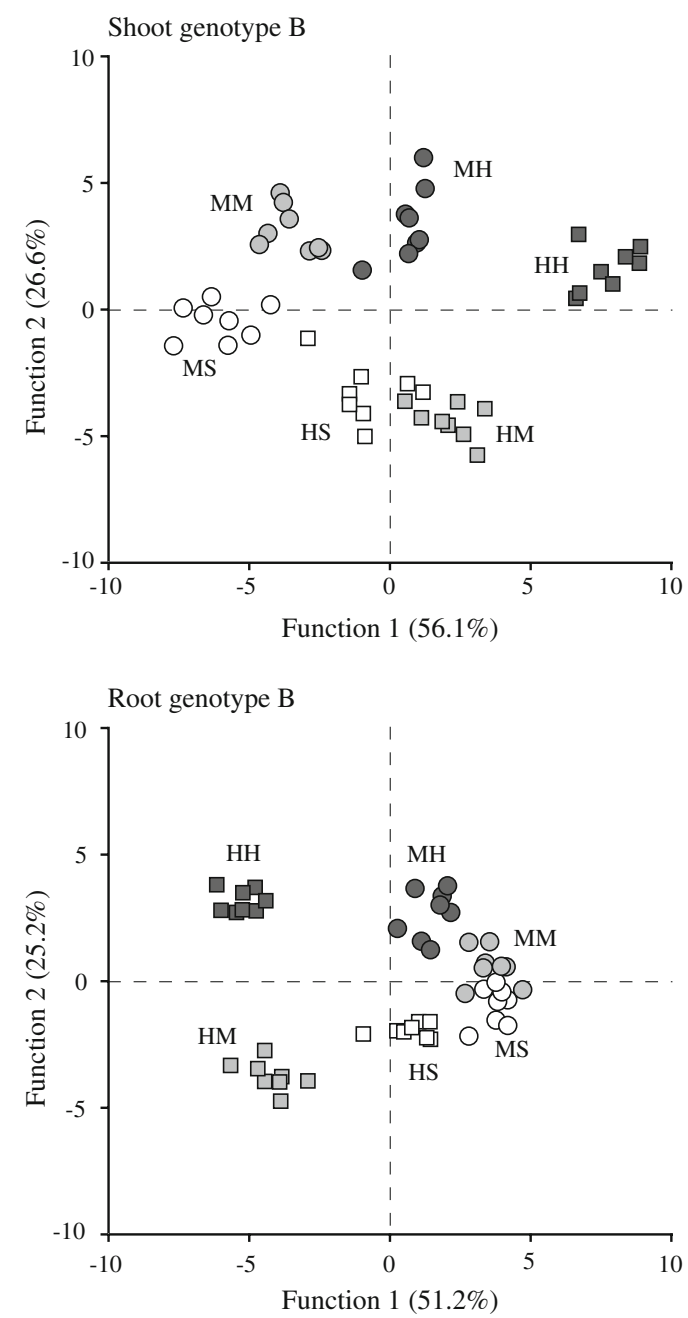

soil inoculated with Heteren soil; $M S=$ Sterilized Meijendel soil; $H M=$ Sterilized Heteren soil inoculated with Meijendel soil; $H H=$ Sterilized Heteren soil inoculated with Heteren soil; $M S=$ Sterilized Heteren soil 
Shoot genotype A

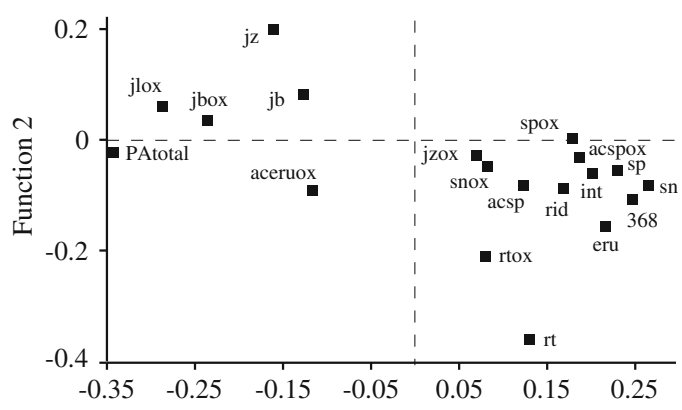

Root genotype A

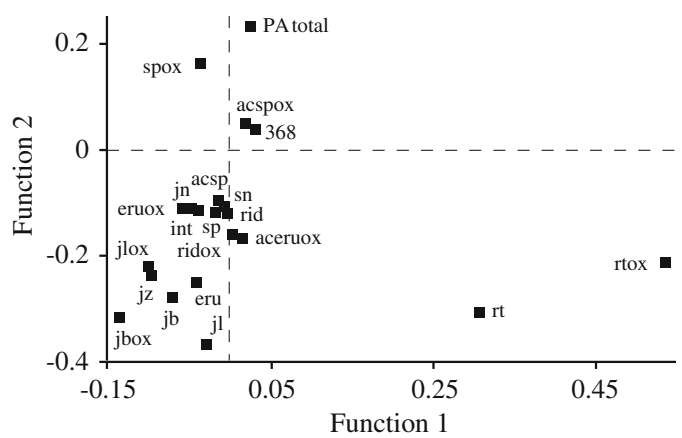

Fig. 4 The correlations of each individual PA with the first two discriminant functions. All PAs shown in these structure matrixes showed significantly different group means (ANOVA $P<0.05$ ). PA total $=$ total PA concentration, $s n=$ senecionine, snox $=$ senecionine $N$-oxide, $s p=$ seneciphylline, $s p o x=$ seneciphylline $N$-oxide, $a \operatorname{csp}=$ acetyl-seneciphylline, acspox = acetylseneciphylline $N$-oxide, int $=$ integerrimine, intox $=$ integerrimine $\mathrm{N}$-oxide, $r t=$ retrorsine, $r$ tox $=$ retrorsine $\mathrm{N}$-oxide, $\mathrm{eru}=$

each individual PA with the first two discriminant functions.

Roots of genotype A: discrimination of the three treatments (sterile and 2 inocula) was mainly explained by function 1 and discrimination of the two soil-types by function 2 . Function 1 classified 59.4\% correctly and together with function 2 the discriminant analysis classified in total $82.9 \%$ of the cases correctly (Fig. 3). So, the inoculum treatment had more effect on the belowground PA composition than soil-type.

Shoots of genotype A: discrimination on soil-type was mainly explained by function $1(52.0 \%$ classified correctly) and discrimination on inoculum treatment by function 2 (30.1\% classified correctly), meaning that soil-type had more influence on the aboveground PAs than the inoculum.

Roots and Shoots of genotype B: soil-type and inoculum treatment were discriminated by both func-
Shoot genotype B

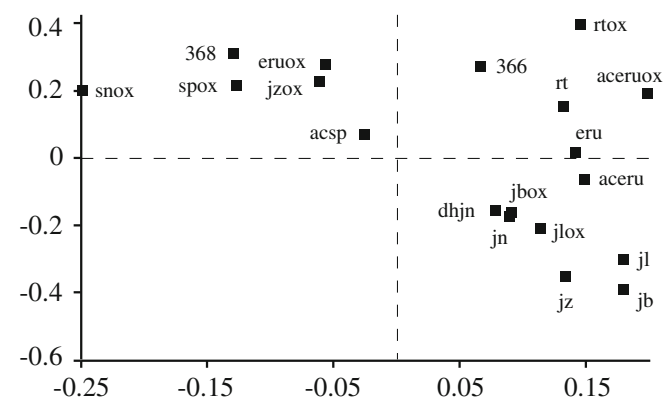

Root genotype B

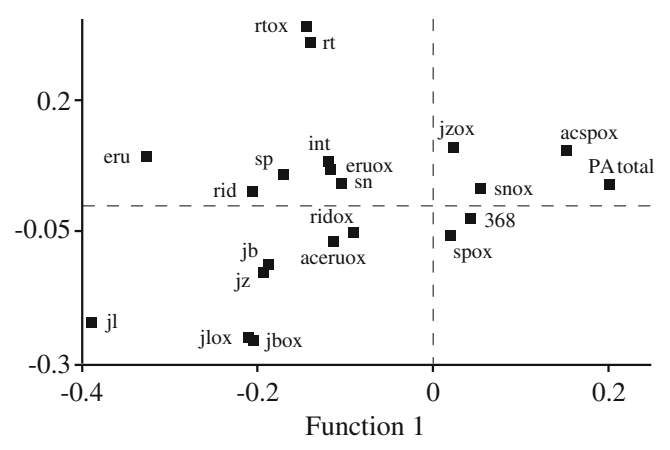

erucifoline, eruox $=$ erucifoline $N$-oxide, aceru $=$ acetylerucifoline, aceruox $=$ acetyl-erucifoline $N$-oxide, $j b=$ jacobine, jbox $=$ jacobine $N$-oxide, $j z=$ jacozine, $j z o x=$ jacozine $N$-oxide, $j l=$ jacoline,$j l o x=\mathrm{jl} N$-oxide,$j n=$ jaconine, jnox $=$ jaconine $N$ oxide, $\operatorname{dhjn}=$ dihydro-jaconine, rid $=$ riddelliine, ridox $=$ riddelliine $N$-oxide, $368=$ PA $N$-oxide with molecular mass 368 (eruciflorine)

tions to the same extend. Thus the effects of soil-type and inoculum treatment on the alkaloid composition in the plant were equally strong.

The relative concentration of jacobine, jacobine $N$ oxide, jacoline, jacoline $\mathrm{N}$-oxide and jacozine, was significantly higher in Heteren soil (HS, HM, HH), as is shown by combining the information provided in Figs. 3 and 4. For example, the mean relative shoot concentration of both jacobine and jacobine $N$-oxide in genotype A on Heteren soils was around $51 \%$ of the total PA concentration while on Meijendel soils around $32 \%$ of the total PA concentration consisted of this PA. The mean relative root concentration of both jacobine and jacobine $N$-oxide in genotype A was more than twice as high in Heteren soils compared to Meijendel soils, 4.4 and $1.8 \%$ respectively.

Remarkably, in roots and shoots of both genotypes, the concentration of retrorsine $\mathrm{N}$-oxide was highest 
in the soils treated with Heteren inoculum ( $\mathrm{MH}$ and $\mathrm{HH})$. In genotype A grown on MS and HS soil the mean relative concentration was $0.4 \%$ while for $\mathrm{MH}$ and $\mathrm{HH}$ soils the mean relative concentration was significantly higher, 2.7 and $2.4 \%$ respectively. Also the tertiary amine retrorsine was higher in both sterilized soils treated with non-sterilized Heteren inoculum.

\section{Discussion}

We found that the PAs composition below and aboveground was significantly affected by both soiltype and soil-borne microbial community. The effect on total PA concentration was, however, relatively small.

Plant dry mass was also influenced by both soiltype and soil-borne microorganisms but the changes in the relative concentrations of individual PAs were not associated with these changes in dry mass. For instance, the difference between plant dry mass of plants grown on Meijendel soils was largest between the sterile soil (MS) and the soil inoculated with Meijendel soil (MM). However, the discrimination between these two treatments based on the relative concentration of the individual PAs was not very strong (Fig. 3).

Plant dry mass was highest on sterilized soils (HS and MS) while it was lowest on soils inoculated with the non-sterilized same soil. The negative influence of the 'own' inoculum treatment on plant growth might be the result of a pathogenic effect or the result of competition for nutrients by the introduced microorganisms. The increased occurrence of microorganisms that act as plant pathogens and/or inhibitor microorganisms in the 'own' soil might be due to adaptations to local soil conditions.

After addition of only a small inoculum (5\%) into the 'biologically empty' sterilized own soil, microorganisms may have developed into a community that is capable of reducing plant growth. Inoculation with the other soil may have also introduced potential pathogens, but these pathogens may be less adapted to these new soil conditions compared to potentially pathogen suppressive agents in that same inoculum. This also holds for the sterilized soils that were not inoculated. The soil probably did not remain sterile in the course of the experiment, but will have been inoculated randomly by air-borne microorganisms.
At this point we cannot draw any hard conclusions on the above mentioned since the soil microbial community is a black box. Although we clearly show an overall effect of the microbial community on PA composition of the plant we cannot pinpoint which microorganisms caused these effects.

Soil-type and soil-borne microorganisms influenced the composition of defense compounds in the roots and shoots of the plant primarily by changing the concentration of specific PAs. Changes in the concentration of individual PAs aboveground may attract specialist herbivores while deterring generalists (Macel and Vrieling 2003; Macel et al. 2005; Macel and Klinkhamer 2009). In our study, the levels of retrorsine and retrorsine $N$-oxide were raised in the plants grown on soils inoculated with non-sterilized Heteren soil. Retrorsine $N$-oxide is formed by the addition of a hydroxy group to senecionine $\mathrm{N}$-oxide. We can conclude that this process is stimulated by the Heteren inoculum. In a previous study, retrorsine and retrorsine $\mathrm{N}$-oxide showed to have inhibitory effects on mycelium growth of several plant-associated fungi (Hol and van Veen 2002). In addition to changes in retrorsine and retrorsine $N$-oxide, the levels of jacobine and jacobine $\mathrm{N}$-oxide were raised in shoots of plants grown on Heteren soils, especially sterilized Heteren soil inoculated with Meijendel soil (HM). Jacobine is especially interesting because jacobine was mainly responsible for the relative high amounts of tertiary amines found in the shoots. Tertiary amines are considered as the toxic state (Lindigkeit et al. 1997), by acting as highly reactive alkylating agents (Mattocks 1986). While being toxic for generalist herbivores, several specialists prefer plants containing high levels of jacobine (van Dam et al. 1995; Macel and Klinkhamer 2009). A previous study on soilborne microorganisms showed that $J$. vulgaris plants containing high levels of jacobine alkaloids had a lower fungal diversity in the rhizosphere than $J$. vulgaris plants lacking high levels of jacobine alkaloids (Kowalchuk et al. 2006). Apart from the above, at this stage there is still too less known about the functions of specific alkaloids to predict the ecological consequences of the change in alkaloid composition. Further research on the influence of specific PAs on fungal and bacterial growth in vivo is warranted.

In conclusion this study shows that plants have a more complex chemical defense strategy as previously 
thought. Our results demonstrate that inoculating sterilized soils with only $5 \%$ of non-sterilized soil has a great impact on the plant growth and the plant's defense system. This may have considerable ecological consequences for instance for the invasive success and biological control of plants. In addition this has many practical implications for the design of experiments on plant defense. We will continue to investigate this functional response and the consequences of these changes in chemical defense for plant fitness and the influence on herbivore and pathogen pressure above and belowground.

Acknowledgement We are grateful to Cilke Hermans, Karin van der Veen-van Wijk, Gera Hol, Ciska Raaijmakers and Henk Nell for their technical assistance. We thank Klaas Vrieling for helpful comments on the design of the experiment and earlier draft of this manuscript and Martin Brittijn for the artwork.

Open Access This article is distributed under the terms of the Creative Commons Attribution Noncommercial License which permits any noncommercial use, distribution, and reproduction in any medium, provided the original author(s) and source are credited.

\section{References}

Agrawal AA (1998) Induced responses to herbivory and increased plant performance. Science 279:1201-1202. doi:10.1126/science.279.5354.1201

Betteridge KCY, Colegate SM (2005) Improved method for extraction and LC-MS analysis of pyrrolizidine alkaloids and their N-oxides in honey: application to Echium vulgare honeys. J Agric Food Chem 53:1894-1902. doi:10.1021/ jf0480952

Bever JD (1994) Feedback between plants and their soil communities in an old field community. Ecology 75:19651977. doi:10.2307/1941601

Bezemer TM, van Dam NM (2005) Linking aboveground and belowground interactions via induced plant defenses. Trends Ecol Evol 20:617-624. doi:10.1016/j.tree.2005.08.006

Bezemer TM, De Deyn GB, Bossinga TM, van Dam NM, Harvey JA, van der Putten WH (2005) Soil community composition drives aboveground plant-herbivore-parasitoid interactions. Ecol Lett 8:652-661. doi:10.1111/j.14610248.2005.00762.x

Dicke M, Hilker M (2003) Induced plant defenses: from molecular biology to evolutionary ecology. Basic Appl Ecol 4:3-14. doi:10.1078/1439-1791-00129

Frischknecht PM, Schuhmacher K, Müller-Schärer H, Baumann TW (2001) Phenotypic plasticity of Senecio vulgaris from contrasting habitat types: growth and pyrrolizidine alkaloid formation. J Chem Ecol 27:343-358. doi:10.1023/ A: 1005684523068
Gange AC, Stagg PG, Ward LK (2002) Arbuscular mycorrhiza fungi affect phytophagous insect specialism. Ecol Lett 5:11-15. doi:10.1046/j.1461-0248.2002.00299.x

Hartmann T, Dierich B (1998) Chemical diversity and variation of pyrrolizidine alkaloids of the senecionine type: biological need or coincidence? Planta 206:443451. doi:10.1007/s004250050420

Hol WHG, van Veen JA (2002) Pyrrolizidine alkaloids from Senecio jacobaea affect fungal growth. J Chem Ecol 28:1763-1772. doi:10.1023/A:1020557000707

Hol WHG, Vrieling K, van Veen JA (2003) Nutrients decrease pyrrolizidine alkaloid concentrations in Senecio jacobaea. New Phytol 158:175-181. doi:10.1046/j.1469-8137.2003. 00710.x

Karban R, Baldwin IT (1997) Induced responses to herbivory. University of Chicago Press, Chicago and London

Klironomos JN (2002) Feedback with soil biota contributes to plant rarity and invasiveness in communities. Nature 417:67-70. doi:10.1038/417067a

Kowalchuk GA, Hol WHG, van Veen JA (2006) Rhizosphere fungal communities are influenced by Senecio jacobaea pyrrolizidine alkaloid content and composition. Soil Biol Biochem 38:2852-2859. doi:10.1016/j.soilbio.2006.04. 043

Lindigkeit R, Biller A, Buch M, Schiebel HM, Broppre M, Hartmann T (1997) The two faces of pyrrolizidine alkaloids: the role of tertiary amine and its N-oxide in chemical defense of insects with acquired plant alkaloids. Eur J Biochem 245:626-636. doi:10.1111/j.1432-1033.1997.00626.x

Macel M, Vrieling K (2003) Pyrrolizidine alkaloids as oviposition stimulants for the cinnabar moth, Tyria jacobaeae. J Chem Ecol 29:1435-1446. doi:10.1023/ A:1024269621284

Macel M, Klinkhamer PGL (2009) Chemotype of Senecio jacobaea affects damage by pathogens and insect herbivores in the field. Evol Ecol

Macel M, Klinkhamer PGL, Vrieling K, van der Meijden E (2002) Diversity of pyrrolizidine alkaloids in Senecio species does not affect the specialist herbivore Tyria jacobaeae. Oecologia 133:541-550

Macel M, Vrieling K, Klinkhamer PGL (2004) Variation in pyrrolizidine alkaloid patterns of Senecio jacobaea. Phytochemistry 65:865-873. doi:10.1016/j.phytochem. 2004.02.009

Macel M, Bruinsma M, Dijkstra SM, Ooijendijk T, Niemeyer HM, Klinkhamer PGL (2005) Differences in effects of pyrrolizidine alkaloids on five generalist insect herbivore species. J Chem Ecol 31:1493-1508. doi:10.1007/s10886005-5793-0

Mattocks AR (1986) Chemistry and toxicology of pyrrolizidine alkaloids. Academic, London

Paul ND, Hatcher PE, Taylor JE (2000) Coping with multiple enemies: an integration of molecular and ecological perspectives. Trends Plant Sci 5:220-225. doi:10.1016/ S1360-1385(00) 01603-4

Steiner AA (1968) Soilless culture. Proceedings of the 6th colloquium of the International Potash Institute, Florence, Italy. 324-341, International Potash Institute, Bern, Switzerland 
van Dam NM, Vuister LWM, Bergshoeff C, de Vos H, van der Meijden ED (1995) The 'raison d'etre' of pyrrolizidine alkaloids in Cynoglossum officinale: deterrent effects against generalist herbivores. J Chem Ecol 21:507-523. doi:10.1007/BF02033698

van Dam NM, Harvey JA, Wäckers FL, Bezemer TM, van der Putten WH (2003) Interactions between aboveground and belowground induced responses against phytophages. Basic Appl Ecol 4:63-77. doi:10.1078/1439-179100133

van der Putten WH, Vet LEM, Harvey JA, Wäckers FL (2001) Linking above- and belowground multitrophic interactions of plants, herbivores, pathogens, and their antagonists. Trends Ecol Evol 16:547-554. doi:10.1016/S0169-5347 (01) 02265-0 van Loon JJA, Bakker PAHM, Pieterse CMJ (1998) Systemic resistance induced by rhizosphere bacteria. Annu Rev Phytopathol 36:453-483. doi:10.1146/annurev.phyto.36.1.453

Vrieling K, de Vos H, van Wijk CAM (1993) Genetic analysis of the concentrations of pyrrolizidine alkaloids in Senecio jacobaea. Phytochemistry 32:1141-1144. doi:10.1016/ S0031-9422(00) 95079-9

Witte L, Ernst L, Adam H, Hartmann T (1992) Chemotypes of 2 pyrrolizidine alkaloid-containing Senecio species. Phytochemistry 31:559-565. doi:10.1016/0031-9422(92) 90038-R

Wuilloud JCA, Gratz GS, Gamble BM, Wolnik KA (2004) Simultaneous analysis of hepatototxic pyrrolizidine alkaloids and $\mathrm{N}$-oxides in comfrey root by LC-ion trap mass spectrometry. Analyst (Lond) 129:150-156. doi:10.1039/ b311030c 